\title{
A FORMAC̣̃O CONTINUADA, O USO DO COMPUTADOR E AS AULAS DE CIẾNCIAS NOS ANOS INICIAIS DO ENSINO FUNDAMENTAL
}

\author{
Wanderlei Sebastião Gabini* \\ Renato Eugênio da Silva Diniz**
}

RESUMO: O presente artigo discute um processo de formação continuada que focou o ensino de Ciências e o uso do computador, considerando a escola como locus de formação. Essa ação formativa voltou-se para professores que lecionavam nos anos iniciais do Ensino Fundamental. A pesquisa foi desenvolvida sob a abordagem qualitativa e orientou-se pela observação participante. Buscou-se caracterizar as práticas educativas considerando a elaboração do conhecimento científico, o desenvolvimento de atividades experimentais e as possibilidades educacionais da informática. Os resultados revelam o envolvimento do grupo em uma postura de investigação e reflexão, bem como a valorização dos espaços coletivos para debate constante em relação às questões do cotidiano da sala de aula e da ação docente.

Palavras-chave: Formação Continuada de Professores; Uso do Computador; Ensino de Ciências.

\section{CONTINUING EDUCATION, COMPUTER USE AND SCIENCE CLASSES IN THE FIRST YEARS OF PRIMARY SCHOOL}

ABSTRACT: The present article aims to discuss a process of continuing education which was focused on Science teaching and computer use considering the school as the locus of training. This process was intended for teachers who taught in the first years of Primary School. The research was developed with a qualitative approach, focusing on participant observation. It was aimed to characterize the educational practices, considering the elaboration of scientific knowledge, the development of experimental activities and the educational possibilities of the Information and Communication Technologies. The results reveal the involvement of the group in an attitude of research and reflection, and the utilization of collective spaces for constant discussion regarding the issues of classroom and teaching action.

Keywords: teachers' continuing education; computer use; Science teaching. 


\section{INTRODUÇÃO}

As aulas de Ciências, para os anos iniciais do Ensino Fundamental, são desenvolvidas em formatos diferentes, dependendo do ano/série em questão. Considerando-se o ensino de nove anos, nos três primeiros os temas relacionados a Ciências são trabalhados em um contexto de alfabetização, sem preocupação direta com os conceitos propriamente ditos (contexto das escolas estaduais paulistas). Para esse período, não há, pelo menos na matriz curricular vigente hoje, aulas de Ciências. Nos dois anos finais dessa etapa do Ensino Fundamental $\left(4^{\circ} \mathrm{e}\right.$ $5^{\circ}$ anos), ao contrário, aparece a disciplina Ciências, que passa a compor a matriz curricular, com número de aulas destinadas a ela. Como os professores que atuam nos anos em que a disciplina de Ciências existe oficialmente na matriz curricular desenvolvem suas aulas? Existe formação para eles que permita um diálogo mais eficaz com os conceitos científicos?

É possível identificar salas de aula cujas ações envolvendo o ensino, incluindo o de Ciências, estão centradas na mera transmissão de conteúdos e fatos. Essa realidade pode colaborar para que a divulgação do conhecimento científico encontre barreiras para se democratizar na sociedade. Maldaner (2003) discute a importância da compreensão, pelos educadores, do papel da ciência na sociedade, e que eles necessitam trabalhar essa realidade para criar possibilidades de mudanças nas estruturas sociais que impedem que a população, como um todo, tenha acesso aos benefícios dessa ciência.

É consensual que o professor precisa ter domínio sobre o tema a ser tratado. No entanto, a formação do professor que atua nos anos iniciais envolve disciplinas relativas à área de Ciências da Natureza, mas que não chegam, entretanto, a fornecer subsídios efetivos para que o futuro professor consiga lidar, de forma tranquila, com os diversos conteúdos que encontrarão na realidade cotidiana.

Considerado esse contexto e ressaltando-se as possibilidades educacionais trazidas com as novas tecnologias, destaca-se a contribuição de Liguori (1997, p. 85) que aponta ter a escola o desafio de incorporá-las, reconhecendo e partindo "das concepções que as crianças e adolescentes têm sobre essas tecnologias", com o propósito de "elaborar, desenvolver e avaliar práticas pedagógicas que promovam o desenvolvimento de uma disposição reflexiva sobre os conhecimentos e usos tecnológicos". Há que se acrescentar que somente professores preparados poderão assumir o compromisso de desenvolver essa proposta reflexiva junto a seus alunos no que diz respeito à compreensão das informações que são disponibilizadas, por exemplo, na internet.

Com base nessas considerações, o presente artigo tem como propósito discutir aspectos relevantes identificados em um processo de formação continuada de professores, que teve a escola como locus para o seu desenvolvimento, e envolveu o tratamento do conhecimento científico em sala de aula, bem como o uso do computador como recurso complementar ao processo de ensino e aprendizagem. 


\title{
2. UM DEBATE SOBRE O ENSINO DE CIÊNCIAS NOS ANOS INICIAIS, A FORMAC̣̃̃O CONTINUADA DE PROFESSORES E O USO DO COMPUTADOR EM SALA DE AULA
}

Ao abordar o ensino de Ciências nos primeiros anos do Ensino Fundamental, destaca-se a colocação de Gallo (2002, p. 20), para quem a aula não está centrada no discurso que o professor possa promover, mas no "posicionamento que assume em seu relacionamento com os alunos, pela participação que suscita neles, pelas novas posturas que eles são chamados a assumir".

Pozo e Crespo (2009, p. 21), discutindo a elaboração do conhecimento científico, apontam a questão de que a ciência não deve ser apresentada aos alunos como um conjunto de saberes prontos e definitivos, de uma maneira com a qual eles possam perceber seu o caráter dinâmico. Reforçam que

\begin{abstract}
a ciência deve ser ensinada como um saber histórico e provisório, tentando fazer com que os alunos participem, de algum modo, no processo de elaboração do conhecimento científico, com suas dúvidas e incertezas, e isso também requer deles uma forma de abordar o aprendizado como um processo construtivo, de busca de significados e de interpretação, em vez de reduzir a aprendizagem a um processo repetitivo ou de reprodução de conhecimentos pré-cozidos, prontos para o consumo.
\end{abstract}

Considerando-se as colocações de Moraes (1998), a construção conjunta e ativa do conhecimento, realizada pelo professor e pelos alunos, requer que o docente crie situações que possam facilitar a aprendizagem e que tenha o devido cuidado em não obstruir o senso natural de curiosidade que os alunos trazem; ao contrário, que incentive os alunos a ampliar essa exploração do mundo. Por meio da expressão oral, dos relatos, da organização de observações, o aluno está em contato íntimo com a língua oral e escrita, o que colabora com seu desenvolvimento integral.

Não se pode, também, ignorar os conhecimentos que aluno traz ao chegar à escola, os conhecimentos prévios, já que eles serão componente essencial na organização do ensino para se trabalhar os conteúdos escolares, inclusive considerando-se sua relevância. Lahera e Forteza (2006, p. 34) reforçam que as crianças chegam à escola com crenças sobre o funcionamento do mundo, antes que a ciência formal tenha sido apresentada e elas; por isso, o docente precisa promover um "clima de aprendizagem", o que permitirá a essas crianças refletirem sobre essas ideias particulares que trazem e perceberem que podem existir ideias contrárias às suas, porém, válidas, e, dessa forma, colaborar com a revisão ou transformação conceitual.

Para Ramos (2008, p. 69), ao se proporcionar oportunidade para que os alunos ocupem, efetivamente, o espaço da sala de aula "como sujeitos da aprendizagem”, eles desenvolverão as atividades de forma prazerosa, além de se sentirem "autores da aula". Normalmente, o que se observa é que esse espaço é centrado no professor, e isso gera certa apatia e não participação dos alunos durante as aulas, fato que pode ocorrer de forma inconsciente por parte do docente. Ramos (ibid. p. 72) destaca, ao se referir ao exercício dos questionamentos instigados durante as aulas, que: 
As perguntas que os alunos apresentam como suas, expressando desejos, intenções de aprender e interesses, são muito relevantes para o professor como sinalizadoras do que os alunos conhecem e sabem, mas também do que eles não conhecem. São, por isso, matéria-prima para a mediação e balizadoras dos procedimentos a serem adotados. Esses questionamentos são fundamentais para a construção de novos argumentos e para a consolidação do processo de comunicação em aula...

Zanon e Freitas (2007), ao discutirem as aulas de Ciências nas séries iniciais do Ensino Fundamental, destacam que as práticas adotadas pelos docentes, "até mesmo de forma inconsciente", compreendem "opções metodológicas engessadas", deixando de lado vivências de questionamentos, observações e experimentos. Segundo as autoras:

Para superar o senso comum e as concepções alternativas dos alunos, é necessário um corpo de conhecimentos mais robusto por parte dos professores e o desenvolvimento de diferentes formas de lidar com os problemas que surgem, algo que eles também irão construindo. Conseqüentemente, cabe ao aluno (aquele que investiga) e ao professor (aquele que orienta a investigação) lidarem com as situações de desequilíbrio e com as capacidades cognitivas, buscando a construção de conhecimentos coerentes com as evidências (empíricas ou não) que vão surgindo nas atividades investigativas. (p. 101)

A respeito da problematização nas aulas de Ciências, os Parâmetros Curriculares Nacionais deixam claro que os conteúdos a serem trabalhados precisam ser apresentados como um problema que precisa ser resolvido. Os modelos trazidos pelos alunos poderão, em certos casos, tornar-se insuficientes, e na busca de informações para explicação de determinado fenômeno, deverão ser reconstruídos ou ampliados. Destaca-se, assim, a importância de saber como trabalhar os conteúdos para que os alunos possam compreendê-los da maneira adequada.

Sasseron e Carvalho (2009, p. 141) discutem a importância de que o professor esteja atento e promova um "diálogo científico", cuidando das palavras que permeiam as interações em sala de aula, bem como perceba os conhecimentos que os alunos já possuem. Bizzo (2002, p. 56-60) debate que o professor deve fazer uso dos termos científicos de maneira progressiva, garantindo que sua compreensão esteja acontecendo. Destaca que a terminologia científica "deve ser entendida dentro de seu contexto, com seus significados compreendidos, e deve ser utilizada de forma correta, mesmo que de forma simplificada - mas nunca distorcida - para ser acessível aos estudantes de diferentes idades". Aponta, também, que para aprender ciência, faz-se necessário conhecer alguns nomes, algumas classificações, o que permitirá a compreensão e a atribuição de sentido ao mundo.

Segundo Ostermann e Moreira (1990, p. 178-179), relatos de professoras que atuam nas séries iniciais, focalizando especificamente o conteúdo de Física, dentro de Ciências, apontam a insegurança que sentem ao lidar com conceitos. Isso, para as professoras, relaciona-se com o fato de não ter sido marcante esse estudo na formação inicial, o que é creditado à predominância da teoria em relação às atividades práticas. Os autores apontam que a insegurança das professoras 
aparece nos erros conceituais que cometem e no medo de se exporem, valendo-se de "afirmações vagas e superficiais, para camuflarem o desconhecimento sobre o assunto", bem como assumindo uma forte autocrítica quanto ao ensino praticado.

Considerando-se os aspectos discutidos, referentes ao ensino de Ciências nos primeiros anos do Ensino Fundamental, uma estratégia relevante é a atividade experimental. Segundo Carvalho et al. (2007), os alunos dos anos iniciais apresentam condições de ir além da simples observação e descrição de fenômenos, o que acaba sendo aquilo que o professor espera deles para essa etapa de escolarização. Afirma que as aulas devem ser organizadas e pensadas para que os alunos deixem o plano da contemplação e caminhem para a fase da reflexão e da busca de explicações.

Os livros didáticos de Ciências costumam trazer exemplos de experimentos para determinada ano e, em boa parte das vezes, utilizam materiais de fácil acesso, de uso cotidiano de professores e alunos. Entretanto, a problematização durante o desenvolvimento do experimento, as discussões que poderão ser motivadas e incentivadas, acabam sendo deixadas de lado. Ao professor que adota determinado livro, considerando-se a influência que as obras passam a assumir, de forma com que sua proposta começa a constituir-se em verdade absoluta sem existir outra maneira de desenvolver certos temas, pode parecer que aquele roteiro mais técnico, formado por uma sequência de passos, seria a forma única de trabalhar tal experimento. Mesmo reconhecendo o papel importante que o livro didático desempenha para as mais diversas disciplinas, cumpre-nos destacar que o professor precisa contemplar diferentes propostas para trabalhar com o conhecimento científico, e não desenvolver linha por linha o que o livro didático propõe.

Os recursos tecnológicos adquiriram espaço no cotidiano das pessoas há décadas, e foram incorporados às ações diárias de maneira que não se concebe esse dia a dia sem certas facilidades e comunicações como, por exemplo, a internet. $\mathrm{O}$ computador popularizou-se e está muito próximo de crianças e adultos. $\mathrm{Na}$ escola, entretanto, nota-se certa dificuldade, e podemos dizer, em alguns casos, certa resistência, para que esse recurso seja incorporado, de fato, às salas de aula, e para que seu potencial seja aproveitado pelos professores a favor da aprendizagem dos alunos.

Para Villardi e Oliveira (2005), o contato da criança com o computador deve estar focado na possibilidade de que o usuário possa assumir uma posição crítica e reflexiva. Bizzo (2002, p. 84-85), discutindo a utilização dos computadores, faz colocações importantes quanto às simulações. Aponta que elas "permitem situar um observador em qualquer lugar do mundo, em qualquer dia, para observar o movimento do Sol, ou confeccionar um jornal", além do fato de que "a simulação de experimentos tem a grande vantagem de economizar esforços e ampliar possibilidades". Chama a atenção para a questão de que "a simulação evita expor os alunos a riscos, em experimentos perigosos e permite conferir dados, especialmente se recebidos de outras escolas ou grupos de alunos".

A internet permitiu, graças à sua popularização, a conexão entre pessoas das mais diferentes localidades, e criou a possibilidade de se considerar os ambientes virtuais como elementos auxiliares em processos de formação. Esses 
ambientes possuem diferentes ferramentas interativas, cada uma com possibilidades intrínsecas. Entretanto, como apontam Mehlecke e Tarouco (2003), é fundamental que existam profissionais preparados para atuar com tais recursos, que viabilizem a interação e a cooperação entre os participantes. Considerando as colocações de Azocar (2004), o futuro não dependerá tanto das tecnologias como do que faremos com elas.

Um aspecto importante a ser considerado nesse debate é o fato de que os professores apresentam-se interessados nos programas de formação continuada quando estes sinalizam benefícios que sejam perceptíveis para os seus alunos e para a sua própria atuação em sala de aula. Imbernón (2009, p. 27) aborda essa questão e comenta que, identificadas essas características, os docentes abrem-se para perceber a proposta formativa não como uma "agressão externa", mas como um "benefício individual e coletivo".

Brzezinski e Garrido (2001) analisaram trabalhos produzidos sobre a formação de professores e apontaram algumas evidências encontradas, como, por exemplo, a tendência de que ela passe a "desenvolver-se preferencialmente no âmbito da instituição escolar, na qual o profissional exerce suas atividades", sendo ultrapassada "a idéia de que a formação em serviço seja realizada em treinamentos", rejeitando-se encontros, cursos intensivos e rápidos, e "pacotes encomendados", que normalmente são "produzidos à distância das salas de aula, que não valorizam os saberes construídos pelos professores". Afirmam que esses pacotes "não relacionam os aspectos teóricos aos problemas concretos vividos pelos docentes” (p. 87).

Conforme discute Alarcão (2003, p. 85), para que o professor encontre espaço para refletir sobre sua prática, a escola também necessita ser reflexiva, valorizando o diálogo e a expressão. Guerra (2006) aponta que a escola pode ser uma comunidade de aprendizagem, e não somente de ensino. Define comunidade educativa não apenas como o conjunto de professores, mas inclui pais, mães, alunos, gestores e funcionários. Destaca, ainda, que:

enquanto construção elaborada e intencional, a comunidade não é um simples amalgama de pessoas que desempenham de forma isolada sua tarefa. Queiram ou não, os profissionais do ensino que trabalham em uma escola formam uma unidade de ação que produz efeitos nos destinos das mesmas. (p. 43 - tradução nossa)

As necessidades próprias de cada equipe escolar, referentes ao cotidiano do processo de ensinar e aprender, podem ser o ponto organizador de "grupos de estudo nas escolas", como discute Fusari (1992). Além disso, a rotina de funcionamento pode proporcionar elementos para que os professores aperfeiçoem sua "competência docente-educativa", e isso pode ocorrer, inclusive, com equipe gestora e demais funcionários da instituição (p. 30). Para ele, a competência docente é "uma elaboração histórica continuada".

Guerra (2006, p. 48-49), considera a comunidade crítica de aprendizagem como aquela que consegue estar além de mera executora das normas externas, e que apresenta níveis maiores de criatividade, contextualização, participação, abertura para a comunidade, flexibilidade organizativa e autorreflexão: 
uma comunidade crítica de aprendizagem é capaz de colocar sua própria natureza, sua estrutura e seu funcionamento na mesa de discussão. Não coloca o foco em qualquer outro objeto antes de situá-lo em sua realidade. É coerente consigo mesma e com seus postulados. Para isso descobre as chaves para o seu fazer e planeja com valentia as mudanças (tradução nossa)

Pesquisa desenvolvida por Gabini (2008) analisou um processo de formação continuada de professores que visava promover a inserção da informática nas aulas de Química, sendo pautado na racionalidade prática e na reflexão crítica. No desenvolvimento e conclusões dessa pesquisa, diversas questões foram reveladas, como a importância de que as "ações de formação continuada tenham previstas atividades para serem desenvolvidas pelos professores nas escolas durante o período em que tais ações acontecem". Assim considerado, o contexto escolar passa a ser visto "como parte integrante dos saberes dos professores, o que os tirará da situação de meros espectadores, imprimindo sentido a tais ações (aprendizagem contextualizada)".

Como aponta Hernández (2007), o trabalho conjunto baseado na colaboração favorece o desenvolvimento profissional, uma vez que aumenta a capacidade de reflexão do grupo a respeito da prática. Os professores partindo desses momentos privilegiados, construir metas comuns e promoverem a resolução conjunta de problemas que estão relacionados à comunidade escolar em que atuam.

\section{METODOLOGIA: O CONTEXTO DA PESQUISA}

A proposta da pesquisa teve sua caracterização em torno dos propósitos de uma abordagem qualitativa. Chizzotti (2006), ao descrever a pesquisa qualitativa, aponta que essa modalidade pretende desvendar o sentido de determinados fenômenos e interpretar os significados que as pessoas atribuem para eles.

A escola na qual o trabalho foi desenvolvido, que será denominada CA, pertence à rede estadual de ensino de São Paulo, e está localizada no município de Torrinha/SP. É a única escola desse município a atender os alunos dos anos iniciais do Ensino Fundamental, do segundo ao quinto, visto que a prefeitura municipal atende os alunos do primeiro ano.

Considerou-se que o público-alvo seria constituído pelos professores que lecionavam na $3^{\mathrm{a}}$ série ( $4^{\mathrm{o}}$ ano) e $4^{\mathrm{a}}$ série ( $5^{\circ}$ ano) do Ensino Fundamental, por serem aqueles docentes que atuam com a disciplina Ciências dentro do currículo. Uma professora de $2^{\circ}$ ano demonstrou interesse em participar do grupo, apesar de a disciplina de Ciências não fazer parte da matriz curricular desse ano, por considerar que aborda questões relacionadas a Ciências nos textos de alfabetização com os quais trabalha. Com o interesse demonstrado pela professora e com sua preocupação com as aulas e a abordagem com os alunos, ela também foi integrada ao grupo.

Os encontros do grupo na escola foram viabilizados com a presença do pesquisador durante uma das reuniões de HTPC (hora de trabalho pedagógico coletivo) 
das professoras, que ocorrem semanalmente, sem, contudo, alterar rotinas que a equipe gestora desenvolvia.

Entre um encontro e outro foi utilizado um ambiente virtual de aprendizagem, o Moodle, com as ferramentas de que dispõe, para que a interação pudesse acontecer para complementar reflexões, discutir atividades e promover debate de materiais de apoio (livros, artigos). Semanalmente, ou conforme o ritmo que proposta exigia, um novo bloco de atividades e recursos era disponibilizado aos participantes.

A observação, por parte do pesquisador, foi um elemento decisivo e traduziu, sem intermediação, os aspectos fundamentais desse grupo, de suas expectativas, seu trabalho e suas conquistas. Como coloca Gil (2006), a observação participante possibilita conhecer a vida do grupo vivenciando seu interior, e as situações habituais se mostram autenticamente e de forma instantânea, frente ao que é proposto ou lançado como desafio.

Além dos registros realizados pelo pesquisador, durante e após as reuniões, sistematicamente, como um diário da pesquisa, os procedimentos de coleta de dados envolveram: questionário inicial, questionário final, documento de opinião (sobre a questão de olhar para o trabalho em sala de aula), questionário para a equipe gestora, discussões nos fóruns e chats, diário (via ambiente virtual), tarefa (ferramenta do ambiente virtual elaboração de texto online), material produzido pelos alunos (sobretudo relatórios), sequências didáticas e filmagem de aulas experimentais.

Em relação às professoras participantes do grupo, serão identificadas, nesta análise, por duas letras maiúsculas, para efeito da apresentação dos resultados e da discussão dos dados, preservando-se a identidade de todas as envolvidas na pesquisa. Dadas as diversas fontes de coleta de dados, o que beneficia a pesquisa com uma variedade de detalhes e de expressões dos participantes, foram estabelecidas duas grandes categorias para a análise de dados, que também orientaram a discussão teórica: o ensino de Ciências nos anos iniciais e a formação de professores. Após a leitura de todo o material coletado e a identificação das ideias principais, houve um segundo momento para agrupar aquelas que traduziam pontos semelhantes e estabelecer subcategorias dentro de cada uma das duas categorias principais.

Essas subcategorias indicam particularidades emergentes dentro de cada categoria e permitem constituir as singularidades do grupo, a relação do processo de formação continuada com a ação docente cotidiana e os pontos principais que foram identificados como mudanças ou incorporações trazidas ao grupo de professoras.

\section{4- DISCUTINDO O PROCESSO DE FORMAC̣ÃO CONTINUADA}

O foco na formação continuada de professores, ponto principal da pesquisa, demonstra a necessidade de analisar o contexto em que atuam os docentes, procurando revelar como se relacionam com os recursos que podem trazer novo direcionamento para as aulas e como se organizam para dialogar sobre a sua prática. 
Um questionamento da pesquisa fez referência a como as aulas de Ciências poderiam estar sendo trabalhadas nos anos iniciais do Ensino Fundamental. Destacam-se, a seguir, dois comentários.

Que bom que vamos trocar experiências sobre como trabalhar Ciências em sala de aula; gostaria de partilhar com vocês uma insegurança; já aconteceu de minhas aulas ficarem um pouco a desejar, pois não pesquisei o suficiente para informar e tirar as dúvidas dos meus alunos. Percebo que agora com a ajuda das colegas, também pesquisa na internet e procurando trabalhar concretamente percebo que os alunos entendem melhor e o que não sei não tenho vergonha de dizer que vou pesquisar. (prof ${ }^{a} . \mathrm{VM}$ )

Gosto de trabalhar com Ciências, porém, há muitos anos que só trabalho com $1^{\mathrm{a}}$ e $2^{\mathrm{a}}$ séries, onde não encontro tanta dificuldade. Agora, trabalhar com Ciências $\operatorname{com~} 3^{\mathrm{a}} \mathrm{e} 4^{\mathrm{a}}$ séries já acho mais complicado, me sinto insegura, preocupada em não estar preparada para responder certos questionamentos dos alunos em sala de aula, não poder sanar suas dúvidas naquele momento. Levar os alunos a fazer experiências é interessante para eles e para o professor também, tornando a aula mais atraente, com maior participação de todos. (prof ${ }^{\mathrm{a}}$. DG)

Esses relatos presentes no fórum permitem a identificação de alguns pontos fundamentais. Um deles refere-se à insegurança ou à falta de preparo para trabalhar temas de Ciências. Acredita-se que esse detalhe fornece pistas sobre uma das indagações apresentadas no início deste trabalho, ou seja, como os professores desenvolvem suas aulas, como se relacionam com os conceitos científicos envolvidos? Se a insegurança se faz presente, se a formação não permite esse amparo conceitual, podemos ter situações nas quais o professor deixe de abordar certos temas, de discutir determinados assuntos com os alunos, inclusive deixando de preparar-se para tal. Ostermann e Moreira (1990) destacam que em relatos de professoras das séries iniciais, essa sensação de insegurança é apontada, seja em erros conceituais cometidos ou no medo de se exporem.

As colocações parecem remeter à figura do professor como o detentor do saber, como aquele que não pode expor dúvidas, pois a insegurança relaciona-se às deficiências na formação inicial e no receio de não conseguir responder aos alunos. Talvez, para o professor dos anos iniciais isso se acentue por conta da assumirem a figura de ídolos das crianças, "pessoas infalíveis".

Após esse primeiro fórum, o artigo "A Química no Ensino Fundamental de Ciências" (Lenir B. Zanon e Eliane M. Palharini) foi apresentado ao grupo, com a proposta de levantamento de aspectos que chamavam a atenção das professoras. Destacamos que nem todas participaram individualmente dessa proposta, que foi concretizada via ambiente virtual. Nesse momento, pareceu que a introdução de materiais para reflexão, para apoio teórico ao grupo, teria que superar a barreira da intimidade com a leitura e o estudo, e mesmo a barreira da elaboração de um pequeno texto como resposta à proposta:

Após a leitura do artigo, concordamos que quando os conteúdos fazem parte do cotidiano, despertam o interesse e a motivação dos alunos. Também através dos temas abordados em 
Ciências, nas $3^{\mathrm{a}} \mathrm{s}$ e $4^{\mathrm{a}} \mathrm{s}$ séries, é possível iniciar os alunos no conhecimento químico, familiarizando-os com termos e conceitos de Química. Ao realizar experiências e se utilizar de conhecimentos próximos, a criança sistematiza e amplia seus conhecimentos, aprendendo de forma significativa. (profas. FC, MM, CG, RB, EC, VM)

Um aspecto que se faz presente na colocação é a valorização dos conhecimentos prévios dos alunos, uma condição essencial para a elaboração do conhecimento científico, conforme destacam Lahera e Forteza (2006). É fundamental que o professor incorpore essa prática, de fato, em seu trabalho cotidiano. Não se trata de apresentar conceitos elaborados, de nível de compreensão incompatível com a idade dos alunos, simplesmente por se tratar das aulas de Ciências. Bizzo (2002), nesse sentido, destaca a questão do uso progressivo dos termos científicos.

Em outro fórum, trabalhou-se o primeiro capítulo do livro Ciências para as séries iniciais e alfabetização - "O ensino de Ciências nas séries iniciais". Existem importantes elementos nesse fórum, uma vez que já havia decorrido certo tempo desde o início dos encontros do grupo, e já existe certa familiaridade com o ambiente virtual. As participações foram mais efetivas, de forma mais natural e com "diálogo" entre os participantes. Apresentamos algumas participações nesse fórum:

Vários aspectos me chamaram atenção, um deles foi que a criança só aprende se ela puder explorar o seu meio, envolvendo-se ativamente na construção do seu próprio conhecimento. Que a função do professor é ficar ao lado do aluno, aprendendo junto, desafiando e incentivando-o para que ele próprio faça suas descobertas. Também que o ensino de Ciências não exige equipamentos sofisticados nem requer que o professor conheça as respostas de todas as questões que propõe aos alunos. Concluindo o ensino de CIẾNCIAS nas séries iniciais deve procurar conservar o espírito lúdico através de atividades desafiadoras e inteligentes. (prof ${ }^{\mathrm{a}}$. CG)

Vários aspectos me chamaram atenção, mas o principal é que o professor deve criar condições para que o aluno construa o próprio conhecimento. Quando a criança vivencia as experiências o espírito investigativo serve como incentivo na busca das respostas. Portanto, o professor deve ser mediador e provocador desse espírito investigativo, para que a partir daí a criança passe então a observar, construir, experimentar, etc. (prof ${ }^{a}$. FC)

A maneira de promover a condução da aula esteve presente em vários pontos dessas colocações: a valorização da investigação por parte dos alunos, colocando-os como sujeitos no processo de construção do conhecimento, desde que guiados pela mediação adequada do professor, o cuidado com as atividades para que não deixem de lado o espírito lúdico, sustentado pela curiosidade natural que as crianças trazem a respeito das situações que as cercam no dia a dia. Pozo e Crespo (2009) apontam a importância de que o aluno perceba o caráter dinâmico da ciência.

Em uma atividade envolvendo o estudo de reações químicas, o grupo sugeriu o trabalho com o tema ferrugem. Utilizamos uma sequência didática proposta em reportagem da Revista Nova Escola, um artigo da própria revista (Como se forma a ferrugem), bem como uma leitura para os alunos, via online, da Revista Ciência Hoje das Crianças (Por que alguns objetos enferrujam?). Essa leitura complementou a 
atividade experimental. Um fórum de socialização foi proposto para que contassem os resultados das aulas, com algumas colocações destacadas a seguir:

A experiência deu bom resultado. Os alunos mostraram-se entusiasmados e participativos, apesar de vários alunos já terem noções do processo da ferrugem, da necessidade da presença da água e do oxigênio para que ela aconteça. O que me chamou a atenção foi o espanto dos alunos quando observaram as tonalidades diferentes que a água apresentou. O lamentável foi que, os que já conheciam, falaram antecipadamente as conclusões do experimento, impedindo, assim, que surgissem muitas perguntas. (prof $\left.{ }^{a} . M R\right)$

Antes de começar a experiência sobre ferrugem fiz perguntas para a classe sobre o assunto e fiquei surpresa com o tanto de informações e situações que os alunos já haviam vivenciado envolvendo a ferrugem. Muitos alunos tinham histórias para contar... Percebi que as crianças têm explicações para os mais diferentes tipos de fenômenos com os quais convivem. (profa. CG)

Os relatos presentes nesse fórum indicam que as professoras estão valorizando, de fato, na condução das atividades experimentais, as contribuições dos alunos, aquilo que já vivenciaram e conhecem sobre diferentes assuntos, e estão incentivando o processo de promover a aproximação entre esses pontos de vista e o conhecimento científico. O registro da surpresa com as colocações dos alunos parece reforçar a adoção desse propósito de investigação. Carvalho et. al (2007) apontam que o processo de investigação pode ser incentivado a partir das séries iniciais.

Vamos considerar, a seguir, diferentes relatos, em fórum promovido para socialização dos resultados das aulas na SAI (Sala Ambiente de Informática), após sua realização.

As crianças estão super motivadas com as aulas de Ciências. Porém, uma das dificuldades encontradas é o número de alunos em cada computador. A animação dos desenhos faz com que elas entendam de forma mais significativa o conteúdo estudado e assim, os relatórios ficam mais simples de serem elaborados. Também os alunos ficam apreensivos sobre o assunto da próxima aula. (prof ${ }^{a}$. CG)

Depois que comecei levar as crianças para a sala de informática nas aulas de Ciências, percebi que elas estão bem mais interessadas. As experiências que fizemos foi um sucesso, pois as aulas são bem mais interessantes diante do computador. É muito legal ver eles (sic) dividirem o computador entre três pessoas, cada um participando na sua vez. Tudo pra eles é mais significativo. Quando termina a aula eles já querem saber o que veremos na próxima. Sem falar que o relatório feito em sala é bem mais fácil de ser elaborado por eles. (prof ${ }^{a}$. EC)

É interessante trazer pontos de vista contrastantes e perceber como eles carregam suas razões de contexto. Uma das professoras comenta que teve dificuldades em acomodar seus alunos nos dez computadores; outra diz que foi bom notar que os alunos se dividiram tranquilamente, revezando a máquina com os demais do grupo sem gerar tumulto. Cada professor e cada sala poderão encontrar a solução que melhor se adapte a eles. Essa troca amigável que ocorre dentro dos 
pequenos grupos de alunos pode acrescentar bastante àquilo que eles observam e percebem na tela do computador, lembrando sempre que o professor precisa mediar tudo isso, e não abandonar os alunos na frente da tela do computador para navegarem sem a menor direção. Para Villardi e Oliveira (2005), é necessário que seja incentivado um posicionamento crítico e reflexivo ao se pensar na relação da criança com o computador.

A proposta de deslocar a ação de formação continuada para dentro da escola encontrou respaldo e apoio na direção da instituição, que mostrou valorizar a formação docente e perceber necessidades que o grupo ainda carrega; além da direção da escola, a coordenação pedagógica também se mostrou aberta para esse trabalho com seus professores.

Ao considerar as reais condições da escola, suas possibilidades e limitações, as professoras perceberam que não havia propostas fantasiosas e impossíveis sendo apresentadas. Esse fator, associado ao anteriormente citado, referente à reciprocidade de intenções que se estabeleceu, propiciou a cooperação e o reconhecimento de um contexto que se preocupava com o ensino e a aprendizagem, de fato, na sala de aula, e não somente nas informações estatísticas sobre o número de professores envolvidos em processos de formação continuada. Como destacam Brzezinski e Garrido (2001), centrar na escola e nos professores as ações de formação continuada é uma tendência presente nos processos de formação continuada.

Tais considerações podem ser percebidas nas opiniões das professoras, quando perguntadas sobre como avaliavam o fato de os encontros do grupo terem acontecido no local de trabalho:

Considero importante. A escola nos proporcionou ambiente favorável e a possibilidade de estarmos todos os professores presentes fazendo juntos estudos, reflexões e troca de experiências. (prof $\left.{ }^{a} . M R\right)$

Foi muito importante esses encontros terem sido desenvolvidos em nosso local de trabalho, pois conseguimos uma maior segurança, experimentando mudanças em nossa prática, num ambiente conhecido. (prof ${ }^{a}$. SN)

Considero que é o ambiente ideal e o horário também, pois acredito que se fosse em horário diverso talvez fosse impossível reunir todo mundo, dificultando as ricas trocas de experiências. (prof $\left.{ }^{a} . \mathrm{VM}\right)$

É o local onde estão todos os envolvidos no grupo de estudos e é onde as mudanças devem ocorrer. (prof ${ }^{\mathrm{a}}$. CG)

Achei ótimo, pois é a maneira mais fácil para todos, é onde desenvolvemos as atividades e onde as socializamos com as colegas. (prof ${ }^{a}$. RB)

$\mathrm{Na}$ observação da professora VM, aparece outro ponto a ser considerado. É a questão de as reuniões terem ocorrido dentro das horas de trabalho pedagógico coletivo, as HTPCs, por tratar-se de um espaço destinado à formação do professor, e muitas vezes utilizado para sessão de recados administrativos, somente. 
Nessa escola, especificamente, essa prática não é a que se observa na condução dessas reuniões, ou seja, assuntos relacionados à sala de aula e ao professor são a tônica dos encontros. Fusari (1992) debate essa questão da valorização dos encontros existentes na escola como espaço especial para discussão do trabalho cotidiano, devendo associar-se à fundamentação teórica.

Entretanto, esse aproveitamento das HTPCs para formação do professor, para estudos, para um aprimoramento teórico e melhoria da prática, acaba ficando em segundo plano em muitas escolas. Por tratar-se de um espaço coletivo, no qual divergências de ponto de vista aparecem e resistências se instalam, parece-nos que recados administrativos acabam sendo uma forma "mais prática" de evitar alguns confrontos de pontos de vista pedagógicos. A busca é pelo trabalho coletivo e pautado em objetivos do grupo e da escola, não nos individuais. Esse é um cuidado que a equipe gestora precisa ter para potencializar adequadamente essas reuniões. Hernández (2007) aponta que o trabalho conjunto baseado na colaboração favorece o desenvolvimento profissional. Além desse aspecto, e reforçando a valorização das HTPCs, Guerra (2006) e Alarcão (2003) enfatizam a necessidade de se promover a reflexão permanente sobre a prática.

Em relação ao grupo escola, as professoras destacaram aspectos que consideraram marcantes, para cada uma, como uma espécie de avaliação do trabalho conjunto, como nos exemplos a seguir:

Os aspectos que achei relevantes nesse nosso trabalho foram o uso da informática, tanto para nosso uso, como para dos alunos, as sugestões de atividades e de sites específicos dos temas, a socialização das experiências e as trocas de ideias e opiniões entre nós professoras. Tudo isso trouxe novos saberes, novos olhares para as aulas de Ciências, em benefício de nossos alunos. (prof ${ }^{a}$. RB)

Ter uma pessoa que domina o conteúdo a ser trabalhado nos deu segurança; complementar os temas que já eram trabalhados; ser ouvido em nossas dificuldades; ter tido conhecimento que nunca é tarde para aprender, melhorar e dinamizar nossas aulas. (profa. VM)

Troca de ideias; reais oportunidades de aprendizagem; trabalho coletivo; experiências desenvolvidas; uso da informática; embasamento teórico; aulas bem planejadas; desenvolvimento da capacidade de registro; reflexão sobre os próprios conhecimentos. (prof ${ }^{a}$. CG)

Que precisamos constantemente nos aprimorar através de estudos e troca de experiências; a reflexão de nossa prática como professores e sobre o que se passa nas aulas de Ciências. (prof ${ }^{a}$. MR)

O professor das séries iniciais, de forma geral, possui um envolvimento educacional especial com seus alunos, e promover benefícios na aprendizagem para eles, como comenta a professora $\mathrm{RB}$, torna-se a preocupação docente nas oportunidades de formação continuada. Percebe-se, também, que o olhar sobre as situações vivenciadas durante as aulas, e a colocação destas para o grupo, adquiriu peso maior no cotidiano dessas professoras, tornando-se ação real, concreta e de possibilidade de melhoria na sala de aula. Nesse sentido, Guerra (2006) aponta ser 
possível que na escola estabeleça-se uma "comunidade crítica de aprendizagem".

A questão da incorporação do recurso da informática é um ponto que se configura como uma mudança de postura, sobretudo para alguns que não faziam uso , passando a apropriar-se do computador como um artefato para dinamizar as aulas e torná-las enriquecidas, com novas perspectivas de diálogo pela interação entre diferentes pessoas, com oportunidades de pesquisa e de ampliação dos espaços de informações.

Complementando esses pontos discutidos, é importante destacar que o desenvolvimento de atividades durante a ação de formação continuada, momentos em que os professores atuam explorando-as junto aos alunos, é um fator determinante para resultados positivos desse processo, conforme já destacado por Gabini (2008). Ter diversas propostas e não trabalhá-las em sala de aula, enquanto há contato entre formador e professores, pode acarretar certo sentimento de frustração aos docentes por não ser possível aplicá-las na escola quando retornam, ou por não apresentarem relação com o que o professor está desenvolvendo naquele momento. Foi possível, no caso desse grupo escola, promover ampliações e adaptações para que todos pudessem desenvolver atividades de acordo com aquilo que estava previsto na respectiva série.

\section{CONSIDERACְ̃̃ES FINAIS}

A transformação da escola em locus de formação foi um ponto fundamental para que a equipe escolar se tornasse parceira, por completo, da ação de formação. A equipe gestora conhecendo os objetivos estabelecidos para o trabalho desenvolvido, e as professoras tendo condições de utilizar os espaços de HTPCs para os encontros do grupo escola, criaram possibilidades concretas de se instalar uma comunidade que aprende.

Considerada a importância de ter a alfabetização científica como foco das aulas nos anos iniciais, a formação continuada do professor assume um papel fundamental, dada a limitação que a formação inicial enfrenta quanto às áreas específicas. Não sendo especialistas em cada disciplina em que lecionam, os professores sentem-se inseguros e despreparados para abordar determinados conteúdos, dada a inevitável situação de ter que fazer esclarecimentos aos alunos e enfrentar perguntas inesperadas, ou mesmo por precisar expor algo que não dominam.

Nas discussões do grupo escola, foi possível diagnosticar que as professoras desenvolviam as atividades experimentais quase que mecanicamente, seguindo a "receita" dos livros que adotam. Talvez isso represente a garantia, nem sempre presente, de que tudo dará certo e que imprevistos não ocorrerão. Quando discutimos essa situação e outras abordagens foram lançadas para determinada atividade experimental, foi possível identificar certa surpresa ao perceber que uma pequena mudança no roteiro permanentemente utilizado permitiria trabalhar melhor junto aos alunos, estimular a participação deles e promover a identificação dos conhecimentos prévios e sua reelaboração. 
No que diz respeito ao uso do computador, foi possível perceber que a máquina não era algo distante da realidade das professoras. Porém, o uso prático dela sim. Havia professoras com grande domínio do recurso e outras que o utilizavam timidamente e de forma limitada. Nas aulas, o mesmo foi notado. Algumas professoras já trabalhavam com os alunos na SAI (Sala Ambiente de Informática), de forma frequente, e outras se organizavam para o uso mais centrado em consulta (resultados de avaliações externas, a busca por temas que iriam trabalhar em sala, por exemplo).

Essa postura vem mostrar a importância do grupo escola e do compartilhamento de propostas e desafios, no conjunto de professores, por meio da discussão de cada detalhe que precisa ser planejado para atuar com os recursos tecnológicos. A formação continuada visou um caráter reflexivo em todas as propostas envolvendo a prática docente, incluindo o uso do computador e recursos relacionados a ele, como é o caso das simulações. Essa abordagem reflexiva é sempre um desafio porque a própria formação inicial dos professores não os prepara, adequadamente, para pensar a respeito de sua prática. Sintetizamos, na sequência, alguns aspectos emergentes na pesquisa em questão:

- O desenvolvimento de uma postura diferenciada em relação às atividades experimentais: investigação, discussão e reflexão;

- Um posicionamento diferente para os recursos do computador: planejamento das atividades e discussão com o grupo, antes do trabalho com os alunos. Além disso, um olhar pedagógico se fez presente, ou seja, o que explorar? Oque oferecem?

- A valorização e exploração dos conhecimentos prévios dos alunos e incentivo ao compartilhamento de suas experiências na sala de aula;

- A reflexão sobre a prática: olhar para as ações desenvolvidas em sala de aula;

- O envolvimento da comunidade escolar no processo de formação: professoras, direção e coordenação pedagógica;

- A escola como espaço privilegiado para debate permanente.

O trabalho no grupo de professores possibilita que se instale a cooperação entre os participantes e isso promove oportunidades de melhoria constante, uma vez que são criadas condições através das quais os docentes podem aprender e buscar soluções para os problemas que se vão desenhando no dia a dia. Esse contexto pode colaborar para que o docente atue, de forma decisiva, na preparação voltada à apropriação dos recursos que a sociedade moderna nos apresenta, entre eles o computador e suas inúmeras oportunidades de informações, bem como na valorização do conhecimento científico para a vida dos alunos.

\section{REFERÊNCIAS}

ALARCÃO, I. Professores reflexivos em uma escola reflexiva, 2 ed. São Paulo: Cortez, 2003.

AZOCAR, M. A. Educação, Tecnologia e Política: o caso do Chile. In: TEDESCO, J. C. (Org.). Educação e Novas Tecnologias: esperança ou incerteza? Trad. Claudia Berliner e Silvana Cobucci Leite. São Paulo: Cortez; Buenos Aires: Instituto Internacional de Planeamiento de La Educacion; Brasília: UNESCO, 2004, p.251-255. 
BIZZO, N. Ciências: fácil ou difícil? 2 ed. São Paulo: Ática, 2002.

BRASIL. SECRETARIA DE EDUCAÇÃO FUNDAMENTAL. Parâmetros Curriculares Nacionais: Ciências Naturais. 2 ed. Rio de Janeiro: MEC/SEF, DP\&A, 2000.

BRZEZINSKI, I.; GARRIDO, E. Análise dos trabalhos do GT Formação de Professores: o que revelam as pesquisas do período 1992-1998. Revista Brasileira de Educação, set/out/nov/dez. 2001, n.18. Disponível em: <http://www.anped.org.br/rbe/rbedigital/RBDE18/RBDE18_09_IRIA_ BRZEZINSKI_E_ELSA_GARRIDO.pdf $>$. Acesso em: 7 jan. 2010.

CARVAlHO, A. M. P., et al. Ciências no Ensino Fundamental: O conhecimento físico. São Paulo: Scipione, 2007.

CHIZZOTTI, A. Pesquisa qualitativa em ciências bumanas e sociais. Petrópolis, RJ: Vozes, 2006.

FUSARI, J. C. A formação continuada de professores no cotidiano da escola fundamental. Disponível em:

<http://www.crmariocovas.sp.gov.br/pdf/ideias_12_p025-034_c.pdf>. Acesso em: 31 jan. 2011.

GABINI, W. S. Formação continuada de professores de Química: enfrentando coletivamente o desafio da informática na escola. 2008. Tese( Doutorado) - Faculdade de Ciências, Universidade Estadual Paulista, Bauru, 2008.

GALLO, S. Transversalidade e educação: pensando uma educação não-disciplinar. In: ALVES, N; GARCIA, R. L. (Orgs). O sentido da escola. 3. ed. Rio de Janeiro: DP\&A, 2002. p. 17-41.

GIL, A. C. Métodos e técnicas de pesquisa social. 5. ed. São Paulo: Editora Atlas, 2006.

GUERRA, M. A. S. La escuela que aprende. 4. ed. Madrid: Morata, 2006.

HERNÁNDEZ, A. L. El trabajo en equipo del profesorado. Barcelone: Graó, 2007.

IMBERNÓN, F. Formação permanente do professorado: novas tendências. São Paulo: Cortez, 2009.

LAHERA, J.; FORTEZA, A. Ciências físicas nos ensinos fundamental e médio: modelos e exemplos. Tradução: Antônio Feltrin. Porto Alegre: Artmed, 2006.

LIGUORI, L. M. As novas tecnologias da Informação e da Comunicação no campo dos velhos problemas e desafios educacionais. In: LITWIN, E. (Org.). Tecnologia Educacional: politica, histórias e propostas. Porto Alegre: Artes Médicas, 1997. p. 78-97.

MALDANER, O. A. A formação Inicial e Continuada de Professores de Química: Professores Pesquisadores. 2. ed. Ijuí: Editora Unijuí, 2003.

MORAES, R. Ciências para as séries iniciais e alfabetização. 3. ed. Porto Alegre: Sagra Luzzatto, 1998.

OSTERMANN, F.; MOREIRA, M. A. O ensino de Física na formação de professores de $1^{\mathrm{a}}$ a $4^{\mathrm{a}}$ série do $1^{\circ}$ grau: entrevistas com docentes. Caderno Catarinense de Ensino de Física, Florianópolis, v. 7, n. 3, p. 171-182, dez. 1990

POZO, J, I.; CRESPO, M. A. G. A aprendiragem e o ensino de Ciências. Trad. Naila Freitas. 5. ed. Porto Alegre: Artmed, 2009.

RAMOS, M. G. A importância da problematização no conhecer e no saber Ciências. In: GALIAZZI, M. C. et. al. (Orgs). Aprender em rede na educação em ciências. Ijuí: Editora Unijuí, 2008. p. 57-75.

SASSERON, L. H.; CARVALHO, A. M. P. O ensino de Ciências para a alfabetização científica: analisando o processo por meio das argumentações em sala de aula. In: NASCIMENTO, S. S.; PLANTIN, C. Argumentaşão e ensino de Ciências. Curitiba: Editora CRV, 2009. p. 139-163.

VILLARDI, R.; OLIVEIRA, E. G. Tecnologia na educação: uma perspectiva sócio-interacionista. Rio de Janeiro: Dunya, 2005.

ZANON, D. A. V.; FREITAS, D. A aula de ciências nas séries iniciais do ensino fundamental: ações que favorecem a sua aprendizagem. Ciência \& Cognição, v. 10, p. 93-103, mar. 2007. Disponível em: <http://www.cienciasecognicao.org/pdf/v10/m317150.pdf>. Acesso em: 27 dez. 2009.

Data do Recebimento: 27/03/2011

Data de Aprovação: 24/12/2011

Data da Versão Final: 13/02/2012 